\title{
Repeated allergen exposure of sensitized Brown-Norway rats induces airway cell DNA synthesis and remodelling
}

\author{
M. Salmon ${ }^{+}$, D.A. Walsh ${ }^{\#}$, H. Koto ${ }^{+}$, P.J. Barnes ${ }^{+}$, K.F. Chung ${ }^{+}$
}

Repeated allergen exposure of sensitized Brown-Norway rats induces airway cell DNA synthesis and remodelling. M. Salmon, D.A. Walsh, H. Koto, P.J. Barnes, K.F. Chung. C) ERS Journals Ltd 1999.

ABSTRACT: Chronic inflammation in asthmatic airways can lead to characteristic airway smooth muscle (ASM) thickening and pathological changes within the airway wall.

This study assessed the effect of repeated allergen exposure on ASM and epithelial cell deoxyribonucleic acid (DNA) synthesis, cell recruitment and airway wall pathology. Brown-Norway rats were sensitized and then exposed to ovalbumin or saline aerosol every 3 days on six occasions. After the final exposure, rats were administered twice daily for 7 days with the DNA S-phase marker bromodeoxyuridine (BrdU). Using a triple immunohistochemical staining technique, BrdU incorporation into ASM and epithelium was quantified employing computer-assisted image analysis.

There were $>3$-fold mean increases in BrdU incorporation into ASM from $1.3 \%$ of cells $(95 \%$ confidence interval $(C I) 1.0-1.6)$ in saline controls to $4.7 \%(95 \%$ CI 2.6 6.7) after allergen exposure $(p<0.001)$, and in airway epithelium, from $1.3(95 \% \mathrm{CI}$ 0.6-2.0) BrdU-positive cells $\mathrm{mm}$ basement membrane ${ }^{-1}$ in saline controls to $4.9(95 \%$ CI 3.0-6.7) after allergen exposure $(p<0.001)$. There was increased subepithelial collagen deposition and mucus secretion along with a significant eosinophil and lymphocyte recruitment to the airways.

Increased rates of deoxyribonucleic acid synthesis in both airway smooth muscle and epithelial cells along with changes to the airway wall pathology may precede the establishment of smooth muscle thickening and airway remodelling after repeated allergen exposure in rats. This model seems to be appropriate for studying structural changes within the airways as observed in asthma.

Eur Respir J 1999; 14: 633-641.
${ }^{+}$Thoracic Medicine, Imperial College School of Medicine at the National Heart and Lung Institute, London, UK. "University of Nottingham, Rheumatology Unit. City Hospital, Nottingham, UK.

Correspondence: K.F. Chung

Thoracic Medicine

Imperial College School of Medicine

National Heart and Lung Institute

Dovehouse Street

London SW3 6LY

UK

Fax: 441713518126

Keywords: Airway epithelium airway remodelling airway smooth muscle

allergen challenge

collagen

deoxyribonucleic acid synthesis

mucus

Received: June 301998

Accepted after revision April 221999

This study was supported by SmithKline Beecham Pharmaceuticals, King of Prussia, PA, USA
Asthma is characterized by chronic inflammation in the airway wall consisting of an infiltration of pro-inflammatory cells such as mast cells, eosinophils and T-lymphocytes [1-3]. In addition, other changes relating to the structure of the airways have been reported, including increases in airway smooth muscle (ASM) mass [4], goblet cell hyperplasia [4, 5], epithelial cell disruption [6] and subepithelial fibrosis [7]. ASM thickening in chronic asthmatics has been described as a process involving both smooth muscle cell hyperplasia and hypertrophy [8,9]. The mechanism by which these chronic changes in the airways, also described as a remodelling process, occur are unclear, but they may contribute to bronchial narrowing and airway hyperresponsiveness.

Models of chronic allergic inflammation have been used in animals in order to investigate how structural remodelling may occur in the airways. In both the cat and mouse, chronic allergen exposure has been shown to reproduce many of the features characteristic of those observed in asthmatic airways $[10,11]$. Using sensitized BrownNorway rats, it has been reported that there is an increase in the ASM area following a series of ovalbumin challenges [12]. Recently, three repeated allergen exposures has been shown to increase deoxyribonucleic acid (DNA) synthesis in ASM and epithelial cells. Increases in the ASM area were identified which may have resulted from an increase in cellular hyperplasia [13]. ASM and epithelial proliferation has been reported after chronic allergen exposure in guinea-pigs; however, there was no evidence of increased ASM mass [14].

In the present study, repeated allergen exposure of sensitized Brown-Norway rats has been used as a model of chronic airway inflammation. Lung pathology and cell recruitment following repeated allergen challenge have been investigated for evidence of airway wall structural changes and remodelling. Additionally, a triple staining technique within the same lung section for the localization of DNA synthesis in ASM and epithelial cells was developed. Immunohistochemistry for $\alpha$-smooth muscle actin was used to specifically distinguish ASM and antibromodeoxyuridine (BrdU) for assessing DNA synthesis, while all other non-BrdU positive cells were labelled with a fluorescent nuclear marker. Computer-assisted image analysis was employed for the identification of these three distinguishing labels, and quantification of cells undergoing DNA synthesis was performed within these specific airway structures. 


\section{Methods}

\section{Sensitization and challenges}

Pathogen-free, male Brown-Norway rats weighing 220$250 \mathrm{~g}$ (Harlan, Bicester, UK) were actively sensitized on days 1,2 and 3 using $1 \mathrm{mg} \cdot \mathrm{kg}^{-1}$ intraperitoneal injections of ovalbumin in $0.9 \%$ sterile saline containing $100 \mathrm{mg}$ of aluminium hydroxide used as an adjuvant. Challenges were performed every third day after sensitization, each exposure being $15 \mathrm{~min}$ in duration, with animals receiving six separate challenges in total. Challenges took place in a $0.8 \mathrm{~m}^{3}$ chamber, with free-breathing animals being exposed to either saline or a $1 \%$ ovalbumin aerosol mist produced by a DeVilbiss PulmoSonic nebulizer (DeVilbiss Health Care Ltd., Feltham, UK). The aerosol mist was pumped into the box at a rate of $0.6 \mathrm{~L} \cdot \mathrm{min}^{-1}$ by a small animal ventilator. At all other times, the rats were housed in a caging system receiving only clean filtered air (Maximiser; Thorens Caging System Inc., Hazleton, PA, USA). Four groups of animals were studied ( $n=5-6$ in each group): Group A: saline-injected, saline-challenged. group $\mathrm{B}$ : ovalbumin-sensitized, saline-challenged; group C: saline-injected, ovalbumin-challenged; group D: ovalbuminsensitized, ovalbumin-challenged.

\section{Bromodeoxyuridine dosing}

The DNA marker 5-Bromo-2'-deoxyuridine (BrdU; Sigma Chemicals, Poole, UK) was dissolved in dimethylsulphoxide (DMSO) and further diluted with sterile water, giving a final concentration of DMSO of $<7 \%$. Rats were injected intraperitoneally with a $50 \mathrm{mg} \cdot \mathrm{kg}^{-1}$ dose in $1 \mathrm{~mL}$ of solution at $12 \mathrm{~h}$ intervals for 7 days commencing $24 \mathrm{~h}$ after the final challenge (total of 14 injections).

\section{Tissue collection}

Rats were killed on day 29 using an overdose of sodium pentobarbitone $\left(500 \mathrm{mg} \cdot \mathrm{kg}^{-1} ;\right.$ i.p. $)$. The lungs were rapidly removed and insufflated with optimal cutting temperature Tissue Tek ${ }^{\mathrm{TM}}$ mounting medium (Raymond A Lamb, London, UK) diluted 1:1 with phosphate-buffered saline (PBS). Regions of the left and right lung lobes were mounted on cork blocks with the main bronchi uppermost, snap-frozen in melting isopentane (BDH, Lutterworth, UK) and stored at $-25^{\circ} \mathrm{C}$.

\section{Histological staining techniques}

Martius, scarlet, blue (MSB) staining [15] was used to identify fibrin and collagen in lung sections, and Periodic acid-Schiff (PAS) staining [16] was used to identify mucus in the airways. General histological characteristics were observed using haematoxylin and eosin stained sections (all reagents used were obtained from Sigma and $\mathrm{BDH})$.
Eosinophil major basic protein and CD2+ T-lymphocyte immunohistochemistry and cell counting

For the detection of eosinophils, a mouse monoclonal antibody against human major basic protein (MBP) was used (clone BMK-13; Monosan, Uden, the Netherlands), which is both sensitive and specific for rat eosinophils [17]. Tissue sections, $5 \mu \mathrm{m}$ thick, were fixed in acetone and then incubated with BMK-13 antibody at a dilution of 1:80 for $30 \mathrm{~min}$ at room temperature. A secondary biotinylated horse anti-mouse immunoglobulin (Ig)G monoclonal antibody (Vector Laboratories, Peterborough, UK) was used against the primary antibody and then positive cells were visualized using an avidin-biotin complex reagent conjugated to alkaline phosphatase. Sections stained for CD2+ T-lymphocytes were fixed with acetone and then applied with a mouse anti-rat CD2 monoclonal antibody (pan T-cell marker; Pharmingen, Cambridge, UK) at a dilution of 1:500 for $1 \mathrm{~h}$ at room temperature. A secondary biotinylated goat anti-mouse monoclonal antibody (Vector Laboratories) was used against the primary antibody and positive cells visualized using an avidinbiotin complex reagent conjugated to alkaline phosphatase.

MBP-positive eosinophils and CD2+ T-lymphocytes were visualized using Sigma FAST ${ }^{\mathrm{TM}}$ (4-chloro-2-methylbenzenediazonium/3-hydroxy-2-naphthoic acid 2,4-dimethylanilide phosphate ( $\alpha$-naphthol AS-MX) and fast red TR) in tris-hydroxymethyl-amino methane (Tris) buffer with positive cells appearing red. Sections were counterstained with haematoxylin (BDH) and mounted under glass coverslips. Cell recruitment around the five largest airways in each lung section was assessed as the number of positive cells in the airway wall (consisting of epithelium, submucosa, smooth muscle and lamina propria), and expressed per millimetre of basement membrane measured by computer-assisted image analysis (Sonata; Seescan, Cambridge, UK). Cell counts in parenchyma were assessed as the number of positive cells in five randomly selected low power fields. Examples of histological staining and immunohistochemistry for cell recruitment are shown in fig. 1 .

\section{Bromodeoxyuridine and $\alpha$-smooth muscle actin immuno- histochemistry}

The sequential immunohistochemical procedure used was based on that described by WALSH et al. [18]. Cryostat sections were cut between the first and second division of the main bronchi at an angle perpendicular and lateral to the conducting airways. Sections, $5 \mu \mathrm{m}$ thick, were thawmounted onto glass slides pretreated with Vectabond (Vector Laboratories). Tissue sections were immersed in a $1: 1$ mixture of acetone and methanol for $10 \mathrm{~min}$ at $12^{\circ} \mathrm{C}$ and rinsed then in PBS for a further $10 \mathrm{~min}$. Endogenous peroxidase was blocked by immersing the sections in methanol containing $0.3 \%$ hydrogen peroxide for $20 \mathrm{~min}$ and washed in PBS. Normal horse serum was applied to the sections for twenty min and then followed by the application of a primary anti-BrdU monoclonal antibody (clone BU-1) solution containing bovine pancreas deoxyribonuclease (DNase) I (Amersham International, Buckinghamshire, UK) at $37^{\circ} \mathrm{C}$ for $75 \mathrm{~min}$. A secondary biotinylated rat-adsorbed antiserum to mouse IgG (Vector 

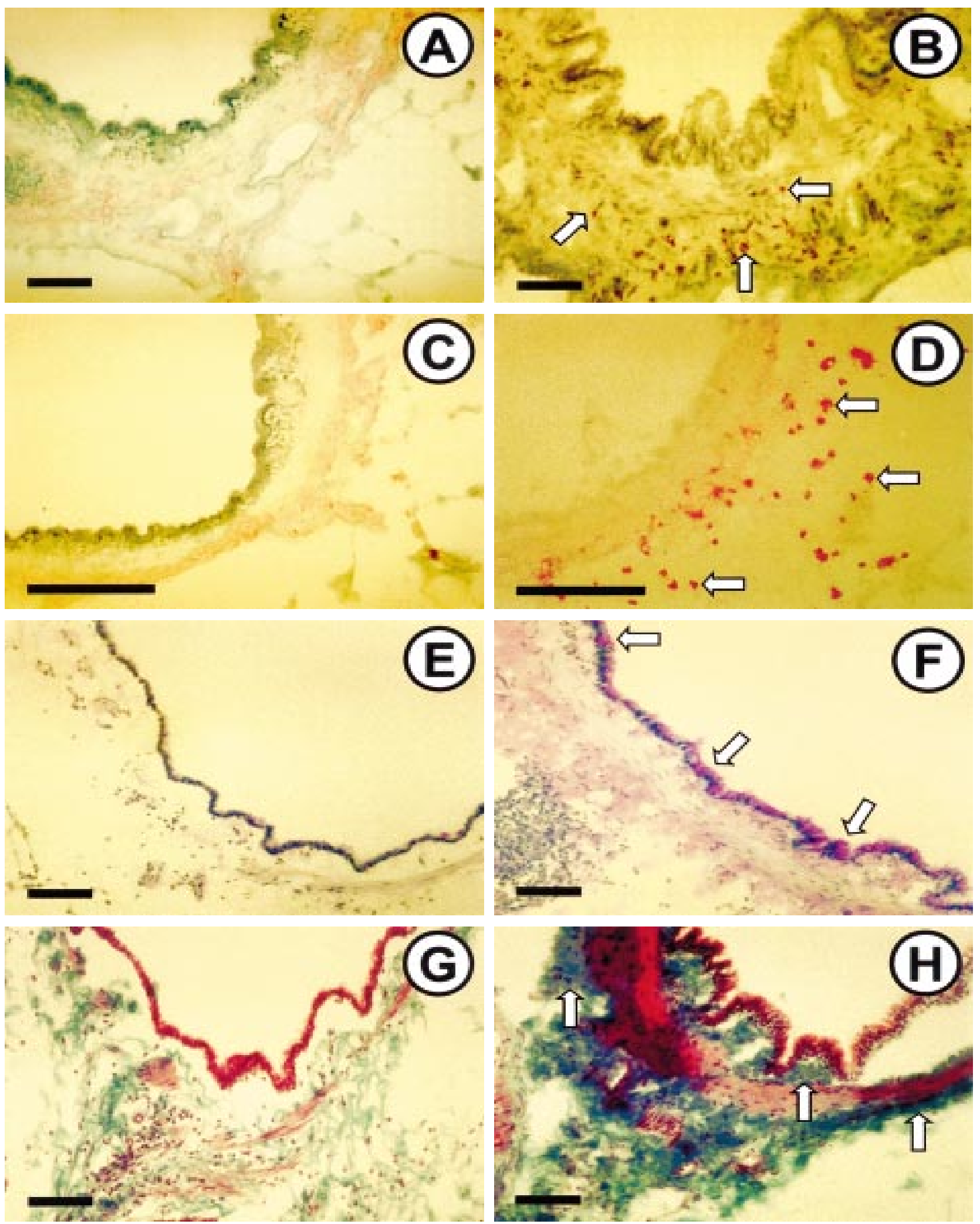

Fig. 1 - Representative photographs of pathological changes to the airways following repeated allergen challenge. B) shows an increased number of $\mathrm{CD} 2+\mathrm{T}$-lymphocytes staining red around the airways (arrows) following repeated allergen challenge compared to a saline-exposed control (A). D) shows increased numbers of MBP-positive eosinophils staining red surrounding the airways (arrows) following allergen challenge compared to a salineexposed control (C). E) (saline) and F) (allergen) are stained with Periodic acid-Schiff (PAS) to detect mucus in the airways. There were marked increases in mucus staining pink (arrows) in the airways and also the size and number of mucus containing goblet cells following repeated allergen exposures. G) (saline) and H) (allergen) are stained with Martius, scarlet, blue (MSB) to detect collagen. There are clear increases in blue staining identifying collagen deposition in the subepithelium and surrounding airway smooth muscle (arrows) after repeated allergen exposure. (Internal scale bars=100 $\mu \mathrm{m}$.) 
Laboratories) was then applied for 30 min, followed by a 45-min incubation with a peroxidase linked avidin-biotin complex solution (ABC-Elite kit; Vector Laboratories). BrdU-positive cells were visualized using 3,3-diaminobenzidinetetrachloride solution (Sigma) with glucose oxidase nickel enhancement to give a blue-black endproduct [19]. Sections were then rinsed and applied with a primary anti- $\alpha$-smooth muscle actin monoclonal antibody (clone 1A4; Sigma) at a concentration of 1:100 for 1 $\mathrm{h}$ at room temperature. A secondary biotinylated ratadsorbed antiserum to mouse IgG (Vector Laboratories) was again applied to the sections, followed by an avidinbiotin complex reagent conjugated to alkaline phosphatase (Vector Laboratories). The $\alpha$-smooth muscle actin staining was visualized using Sigma FAST in Tris buffer to give a red end-product. Nuclei that were not immunoreactive for BrdU were counterstained by application of the fluorescent DNA ligand 4,6-diamidino-2-phenylindole hydrochloride (DAPI) at a concentration of $0.00001 \%$ in PBS containing 0.6\% NP40 (Sigma) for 20
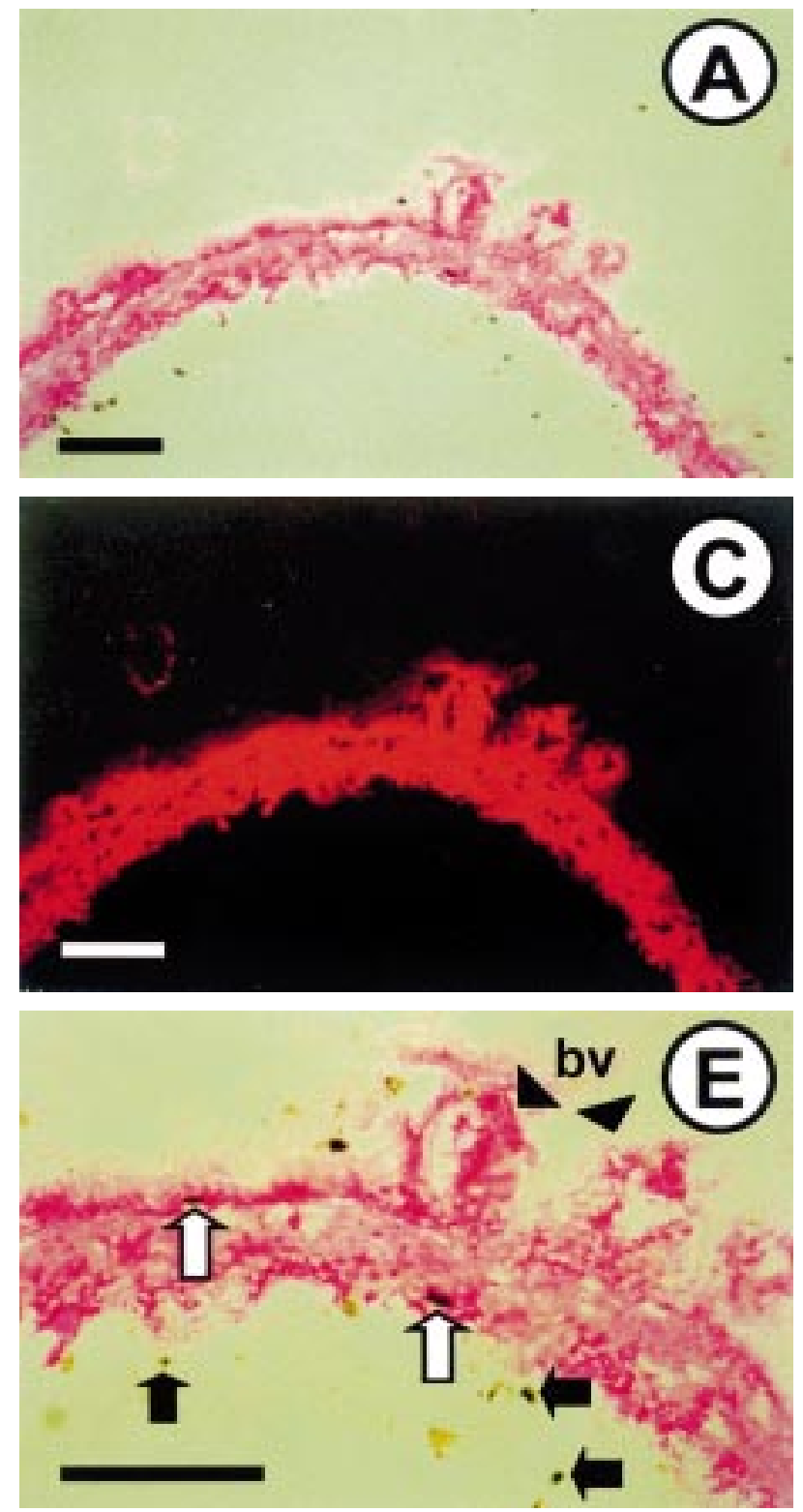

min. Sections were mounted under glass coverslips using 1:1 PBS/glycerol and stored in the dark at $4{ }^{\circ} \mathrm{C}$. Examples of the tissue staining and representative images used for image analysis are shown in fig. 2.

Control tissue sections of spleen, colon and thymus were used to confirm positive BrdU immunoreactivity. Negative control sections for both $\mathrm{BrdU}$ and $\alpha$-smooth muscle actin were performed by treatment with antibodies of the same immunoglobulin class, or in the absence of primary antibody.

\section{Quantification of bromodeoxyuridine incorporation using computer-assisted image analysis}

Each selected airway was quantified under a $\times 10$ objective to measure the internal perimeter, internal area and airway breadth (greatest diameter perpendicular to the longest axis). Images captured through the $\times 120$ objective lens were then used to count BrdU and DAPI labelled cells
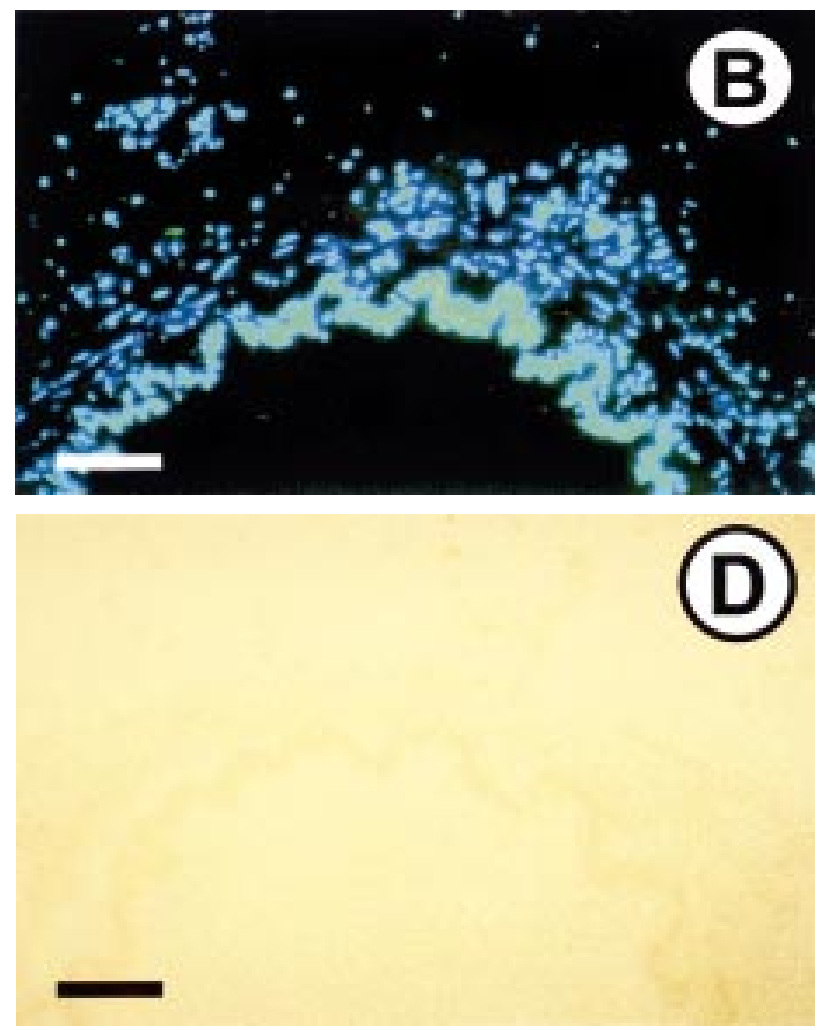

Fig. 2 - Representative photographs of an airway demonstrating the triple staining technique. A), B) and C) represent the same airway stained with three separate markers used to create the images for quantification by image analysis. A) transmitted light image with bromodeoxyuridine (BrdU)-positive nuclei in black (airway smooth muscle (ASM) also appears in red); B) fluorescent image showing all 4,6-diamid no-2-phenylindole hydrochloride (DAPI)-positive nuclei in blue; C) fluorescence image showing $\alpha$-smooth muscle actin immunoreactivity in red which was used to detect areas of airway smooth muscle. D) light transmitted image of an airway from a BrdU-negative control section of lung. E) high-power photograph showing a region of airway from a sensitized and repeatedly allergen-exposed rat. The arrows indicate BrdU-positive cells within the airway smooth muscle (white arrows) and epithelium (black arrows). bv: two associated blood vessels, these would be actively excluded during quantification of ASM. (Internal scale bars $=100 \mu \mathrm{m}$.) 
and measure the smooth muscle area and epithelial basement membrane length. The quantification of images was performed using a Zeiss microscope fitted for both transmitted light and fluorescence imaging (axioplan model; Carl Zeiss, Welwyn Garden City, UK). Images were captured using a monochrome camera at maximum sensitivity and analysed using a Sonata image analysis system (Seescan).

The software was written for the purpose of this study, and the image processing procedure was performed in the following way. The field of interest containing the whole airway was visualized with a $\times 110$ objective using DAPI fluorescence and converted to a monochrome image, and its threshold was determined according to its intensity with the inclusion of all DAPI positive nuclei. The airway of interest was then identified and internal perimeter, crosssectional area and breadth (greatest distance perpendicular to the longest axis) were recorded.

The airway was then visualized using a $\times 120$ objective and images were captured to delineate airway smooth muscle and epithelial area, and BrdU- and DAPI-positive nuclei within these defined areas were counted. In brief, the airway of interest was selected, the transmitted light image containing BrdU positive cells captured and converted to a monochrome image. Without moving the section, a red fluorescence image of the alkaline phosphatase-fast red-labelled $\alpha$-smooth muscle actin immunoreactivity was captured [20]. A blue fluorescence image for DAPI-positive nuclei was then captured and all three images were converted to stored monochrome images. The smooth muscle image threshold was determined according to its intensity to include all $\alpha$-smooth muscle actin-positive regions, the area was measured and a mask created which excluded all regions that were not immunoreactive for $\alpha$-actin. This mask was overlaid onto the transmitted light image of the same area and the number of BrdU-positively stained nuclei counted. The mask was then overlaid onto the DAPI-positive fluorescence image and the number of nuclei counted.

Measurement of epithelial BrdU incorporation was performed in a similar way with the creation of an epithelial mask by interactive delineation of epithelium on the DAPI-fluorescence image, and the number of BrdUpositive nuclei counted. DAPI-fluorescent nuclear profiles overlapped within the epithelium on $5 \mu \mathrm{m}$ thick sections and therefore could not be counted. BrdU-positive nuclei were therefore expressed per unit length of basement membrane.

The BrdU index in airway smooth muscle was measured as the number of BrdU-immunoreactive nuclei divided by the total number of nuclei (BrdU plus DAPI nuclei) within the $\alpha$-smooth muscle actin stained area. Epithelial bromodeoxyuridine incorporation was measured as the number of BrdU positive cells within the DAPI-defined epithelial mask divided by the basement membrane length. Airway smooth muscle thickness was calculated as the total smooth muscle area divided by basement membrane length. Data from five airways were pooled to calculate each index for all individual rats in each experimental group

\section{Number of airways and section variability}

In preliminary experiments, in ovalbumin-sensitized and challenged rats, it was found that the BrdU index in air- way smooth muscle decreased with decreasing airway diameter. BrDU-positive cells were counted in the five largest airways of each of five consecutive lung sections from an ovalbumin-sensitized and challenged rat. The coefficient of variation for the BrdU index in airway smooth muscle was at its minimal when five airways from each section were measured compared to measurements from only one, two, three or four airways. The variability of the ASM BrdU index was calculated in the same airway from the five consecutive lung tissue sections. The co-efficient of variation decreased with an increasing number of sections but the differences were small with the standard error value less than $\pm 15 \%$ of the mean index when comparing one against five consecutive sections. For the quantification criteria, it was therefore decided to take measurements from the five largest airways within a single lung section for all animals in each of the four treatment groups. Using these criteria, the quantification procedure also had a $90 \%$ chance of detecting a $21 \%$ change in airway smooth muscle thickness. All quantification and cell counting was performed with the investigator blinded to the treatment groups.

\section{Analysis of data}

All indices were calculated for individual animals as the weighted mean of the indices from the five largest airways in one section of lung. Mean indices were statistically analysed after logarithmic transformation by one-way analysis of variance (ANOVA), followed by t-tests with Bonferroni correction used to evaluate significant differences between groups. Values are expressed as means (95\% confidence intervals $\mathrm{CI}$ ), with $\mathrm{p}$-values of $<0.05$ considered to be significant.

\section{Results}

\section{Qualitative histological characteristics of lung tissue following repeated exposure}

In the control groups $(\mathrm{A}-\mathrm{C})$, the airways and lung parenchyma looked normal with no evidence of damage or cellular infiltration. In the airways of each of the five sensitized and allergen-exposed rats (group D), there was evidence of oedema, epithelial damage and desquamation with associated wound repair processes. Epithelial cell repair processes included hyperplastic and hypertrophic responses, basement cell metaplasia and regions of poorly differentiated epithelium. Specific PAS staining revealed goblet cell hyperplasia and hypertrophy, along with increased amounts of mucus in the airways compared to the control groups. Cell recruitment in the airways was increased and consisted mainly of lymphocytes, eosinophils and mononuclear cells. The Martius, scarlet, blue staining identified increased deposition of collagen and fibrin in the airways of sensitized and repeated allergen exposed rats compared to the control groups. Dense staining was particularly marked in the submucosa and surrounding the airway smooth muscle, although there was also evidence of collagen deposition within the airway smooth muscle. In the bronchiole-associated lymphoid tissue (BALT) which is localized near the larger airways, there was evidence of 
T-lymphocyte proliferation and an increased area compared to the controls. Migration of cells from these regions was evident and appeared as a disruption to the edges of the BALT borders. Collagen deposition was also evident in BALT tissue. In the parenchyma of sensitized and chronic allergen exposed rats, mature alveolitis was observed with evidence of type 2 pneumocyte cell proliferation. There was also hyperinflation of the alveoli, increased cell recruitment, particularly mononuclear cells, and distinct plasma protein extravasation compared to controls. Examples of lung histology are shown in fig. 1.

\section{Eosinophil and CD2+ lymphocyte recruitment to the lungs}

There was a significant increase in MBP-positive eosinophils and CD2+ lymphocyte recruitment to the airways and parenchyma of sensitized and repeated allergen exposed rats (group D) compared to the three control groups. In the airways, group D had a mean of $9.7 \pm 1.1$ eosinophils.mm basement membrane $\mathrm{e}^{-1}$ compared to $1.51 \pm 0.3$ in group $\mathrm{A}, 2.5 \pm 0.6$ in group $\mathrm{B}$ and $2.3 \pm 0.4$ in group $\mathrm{C}(\mathrm{p}<$ 0.001 versus all three groups). Group D had a mean of $26.9 \pm 2.2 \mathrm{CD} 2+$ lymphocytes $\cdot \mathrm{mm}$ basement membrane ${ }^{-1}$
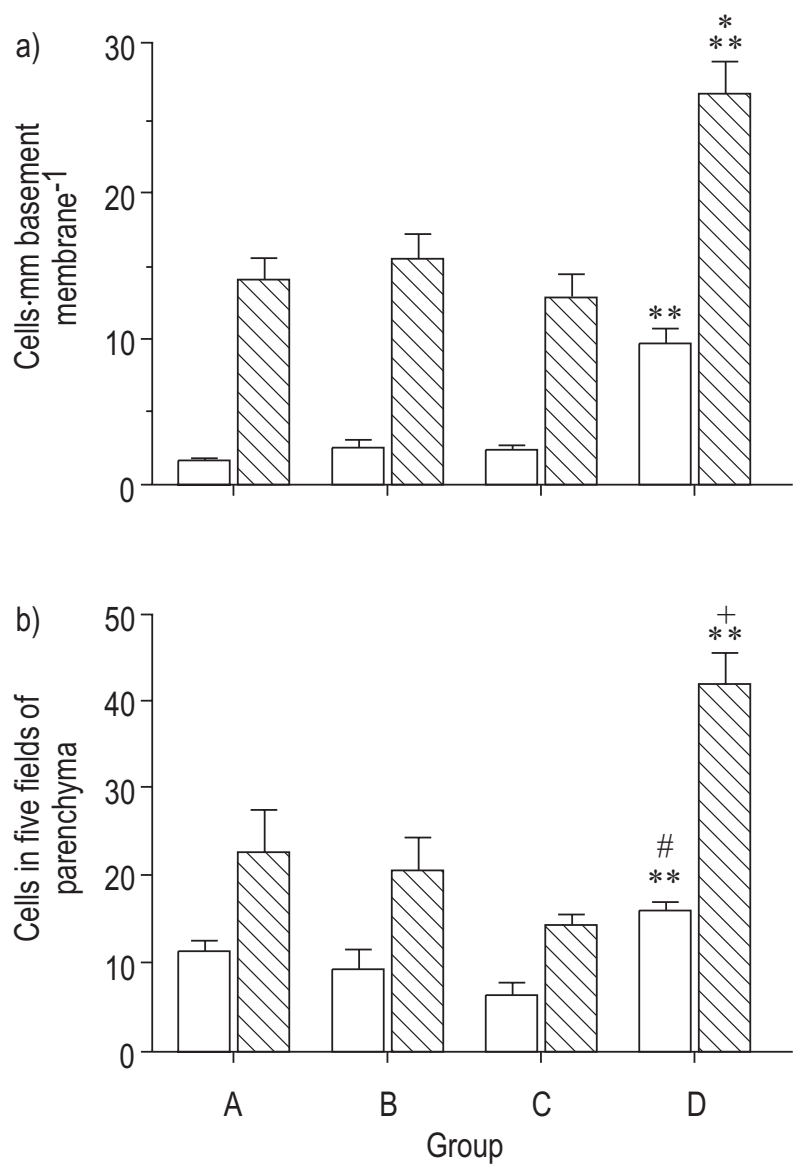

Fig. 3 - Major basic protein-positive eosinophil ( $\square$ ) and CD2+ T-lymphocyte $(\mathbb{\mathbb { Q }})$ recruitment to the airways (a) and parenchyma (b) of sensitized rats following repeated allergen exposure. Group A: saline-injected, saline-challenged; group B: ovalbumin-sensitized, saline-challenged; group $\mathrm{C}$ : saline-injected, ovalbumin-challenged; group $\mathrm{D}$ : ovalbuminsensitized, ovalbumin-challenged. **: $\mathrm{p}<0.001$ compared to groups A, B and $\mathrm{C} ;{ }^{*}: \mathrm{p}<0.01$ compared to group $\mathrm{B} ;{ }^{\#}: \mathrm{p}<0.05$ compared to group $\mathrm{A}$; $+: \mathrm{p}<0.01$ compared to groups $\mathrm{A}$ and $\mathrm{B}$. compared to $14.1 \pm 1.6$ in group $A(p<0.001), 15.5 \pm 1.7$ in group $\mathrm{B}(\mathrm{p}<0.01)$ and $12.8 \pm 1.8$ in group $\mathrm{C}(\mathrm{p}<0.001)$ (fig. $3 \mathrm{a})$. In the parenchyma, group $\mathrm{D}$ also had significant increases in MBP positive eosinophils and CD2+ lymphocytes counted in five low power fields compared the three control groups (fig. 3b).

\section{Bromodeoxyuridine indices of deoxyribonucleic acid synthesis}

Following repeated ovalbumin exposure in ovalbuminsensitized rats (group D), there were increased BrdU indices in both (ASM) and epithelium, $>3$-fold increase compared to each of the control groups $(\mathrm{A}-\mathrm{C})$. In ASM cells, group $\mathrm{D}$ had a mean $(95 \% \mathrm{CI}) \mathrm{BrdU}$ index of $4.7 \%$ (2.6-6.7), compared to $1.2 \%(0.6-1.9)$ in group A $(\mathrm{p}<0.001), 1.3 \%$ $(1.0-1.6)$ in group $B(\mathrm{p}<0.001)$ and $1.1 \%(0.6-1.5)$ in group $\mathrm{C}(\mathrm{p}<0.001)$. There were no significant differences in mean BrdU indices between any of the other groups (fig. 4a). In the epithelium, group D had 4.9 (3.0-6.7) BrdUpositive cells $\cdot \mathrm{mm}$ basement membrane ${ }^{-1}$ compared to 1.1 $(0.3-1.9)$ in group A $(\mathrm{p}<0.01), 1.3(0.6-2.0)$ in group B $(\mathrm{p}<0.01)$ and $1.4(0.1-2.6)$ in group $\mathrm{C}(\mathrm{p}<0.05)$. There
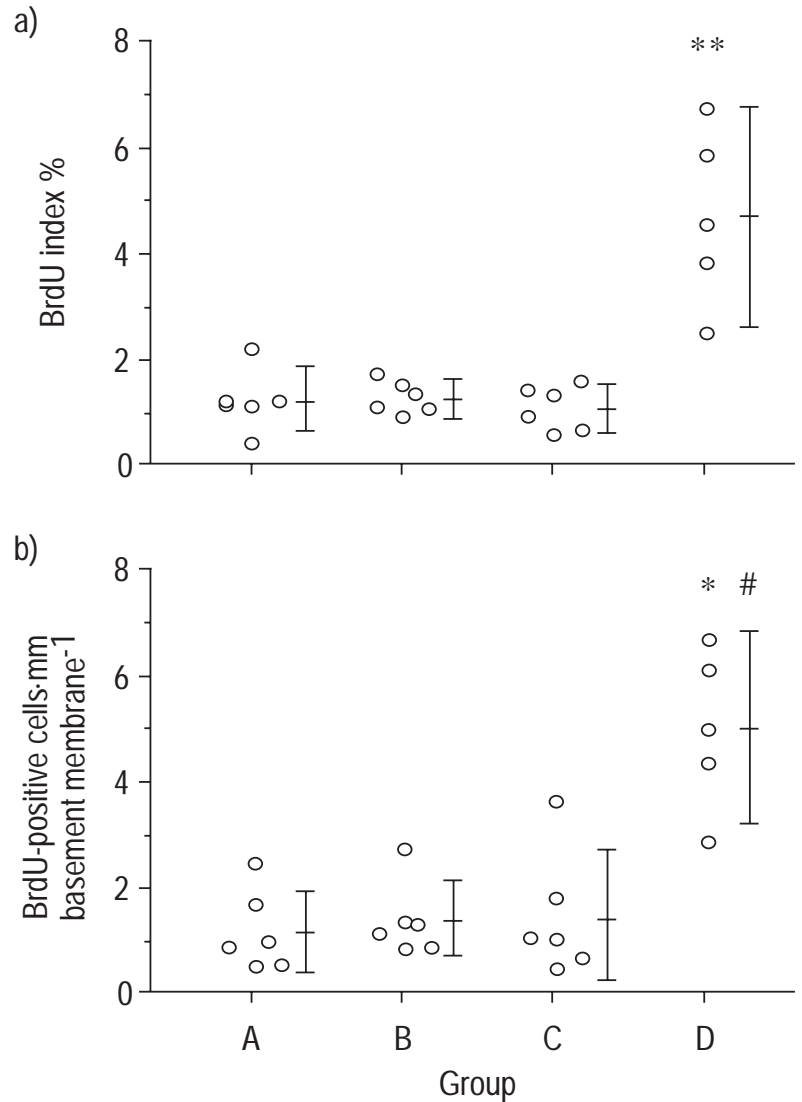

Fig. 4 - Bromodeoxyuridine (BrdU) incorporation indices of DNA synthesis in airway smooth muscle (a) and epithelial (b) cells. Each point represents the mean index for each rat calculated from the five largest airways in a single lung section. The horizontal bars represent the mean value for each group and the error bars the $95 \%$ confidence intervals. Group A: saline-injected, saline-challenged; group B: ovalbumin-sensitized, saline-challenged; group $\mathrm{C}$ : saline-injected, ovalbumin-challenged; group D: ovalbumin-sensitized, ovalbumin-challenged. *: $p<0.01$ compared to groups A and $\mathrm{B} ; * *$ : $\mathrm{p}<0.001$ compared to groups $\mathrm{A}, \mathrm{B}$ and $\mathrm{C} ;{ }^{\#}: \mathrm{p}<0.05$ compared to group $\mathrm{C}$. 
were no significant differences in epithelial BrdU indices between any of the control groups (fig. 4b).

The highest BrdU indices measured in ASM and epithelium following sensitization and repeated allergen challenge (group D) were found in the larger conducting airways, particularly those of $400-800 \mu \mathrm{m}$ in diameter. In this group, there was a positive linear correlation of the BrdU index in the ASM to airway diameter, $r^{2}=0.24$, $(p<$ 0.02 ) (fig. 5a). There was also a positive correlation of BrdU incorporation in airway epithelial cells to airway diameter $\mathrm{r}^{2}=0.49, \mathrm{p}<0.0001$, fig. $5 \mathrm{~b}$. There was no positive correlation of $\mathrm{BrdU}$ indices with increasing airway size in the three control groups $(\mathrm{A}-\mathrm{C})$.

\section{Airway smooth muscle thickness}

Following sensitization and repeated allergen challenge (group D) there was a small but nonsignificant increase in the overall ASM thickness surrounding the airways. Group D had a mean (95\% CI) of $24.7 \mathrm{~mm}(17.3-32.1)$, ASM.mm basement membrane compared to 20.4 (16.224.7) in group A, 20.7 (18.5-22.8) in group B and 22.1 (18.6-25.5) in group C (fig. 6).

a)
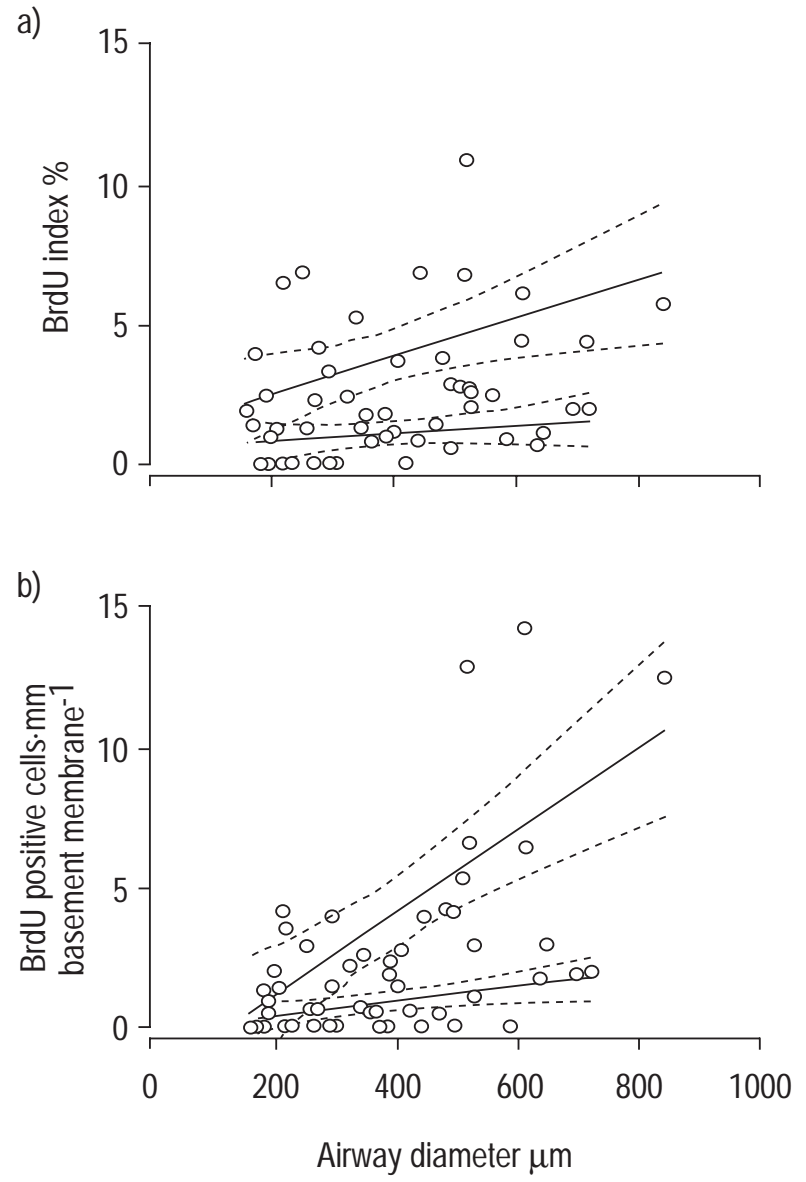

Fig. 5. - Correlation of bromodeoxyuridine (BrdU) incorporation indices with airway size in airway smooth muscle (ASM) (a) and epithelial (b) cells. There was a significant correlation between the BrdU incorporation index and increasing airway diameter in both ASM $(\mathrm{p}<0.02)$ (a) and epithelium $(\mathrm{p}<0.0001)(\mathrm{b})$ in the sensitized and allergen-exposed rats (group D; $O$ ), but there was no significant correlation for the sensitized and saline-exposed rats (group $\mathrm{B} ; \mathrm{O}$ ). - - Lines of linear regression; - - - : 95\% confidence intervals.

\section{Discussion}

The study used a model of repeated allergen exposure of sensitized Brown-Norway rats in order to examine changes in the structure of the airways induced by a series of inflammatory insults. An increase in eosinophil and lymphocyte recruitment into the lungs was detected following repeated allergen challenge. There were marked increases in sub-epithelial collagen deposition, goblet cell number and presence of mucus in the airways 7 days after the final challenge. There were also significant increases in ASM and epithelial cell DNA synthesis as measured by BrdU incorporation.

The pathological changes observed in this model are consistent with some of those observed in the airways of chronic allergic asthmatics. There was a marked collagen deposition in the subepithelium and adventitial regions similar to the patterns of deposition described in the airways of asthmatics [7, 21]. Increased amounts of mucus were also detected following repeated allergen exposure, which may be due to both an increase in the rate of mucus secretion and release, and also due to the clear increase in the number and size of goblet cells observed in the airways. Goblet cell hyperplasia is also a characteristic feature observed in bronchial asthma [5]. A significant recruitment of eosinophils and T-lymphocytes into the airways was also observed after repeated allergen challenge which is a finding consistent with those in bronchial biopsies of asthmatics [1-3].

The technique employed in this study for analysing DNA synthesis using a combination of triple staining procedures and computer-assisted image analysis has the advantage of being able to measure all morphometric parameters within the same tissue section. Additionally, the area occupied by the ASM was well-defined according to specific

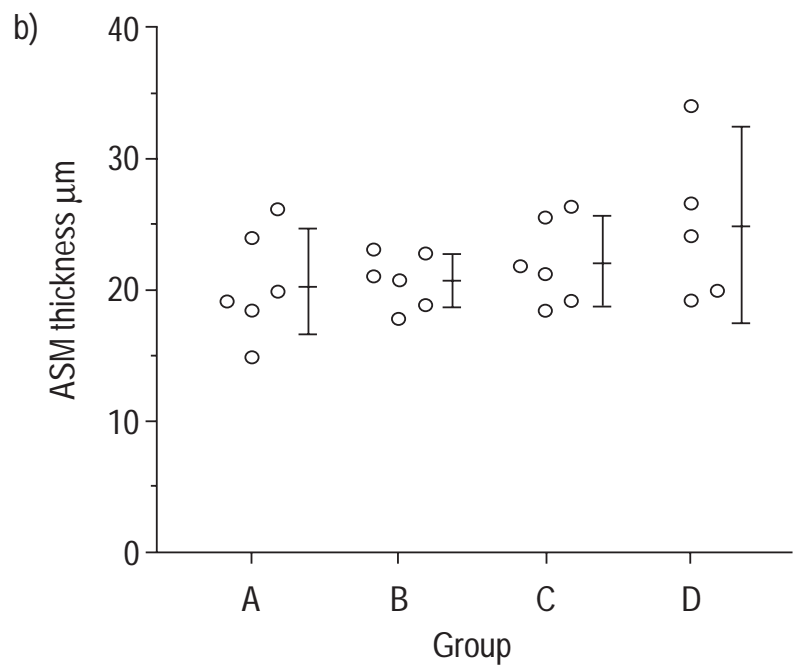

Fig. 6. - Airway smooth muscle (ASM) thickness in sensitized rats after repeated-allergen challenge. Airway smooth muscle thickness was calculated as the total area of ASM surrounding each airway per millimetre of basement membrane. Data are presented as the mean for each animal calculated from the five largest airways in a lung section. After sensitization and repeated-allergen challenge (group D), there was a small but nonsignificant increase in ASM thickness compared to each of the three control groups (A-C). Group A: saline-injected, saline-challenged; group B: ovalbumin-sensitized, saline-challenged; group $\mathrm{C}$ : saline-injected, ovalbumin-challenged; group D: ovalbumin-sensitized, ovalbumin-challenged. 
immunoreactivity by use of antibodies to $\alpha$-smooth muscle actin rather than relying on visual recognition of nonspecifically stained cells. It is possible, however, that myofibroblasts may be stained positive with $\alpha$-smooth muscle actin. It is unlikely such staining affected quantification of the ASM area or BrdU indices, as during the image analysis procedure any staining outside the smooth muscle cell border was actively excluded. Further to this, BrdUpositive cells were only counted if they appeared completely within the defined ASM area. One further possible confounding factor is that inflammatory cells having infiltrated the ASM or epithelium could be counted as falsepositive cells if they had incorporated BrdU. Careful morphological identification of the nuclei of cells was therefore performed in order to distinguish resident ASM and epithelial cells from any infiltrating cells.

Preliminary studies showed that a single allergen exposure of sensitized Brown-Norway rats did not induce significant increases in airway smooth muscle or epithelial cell DNA synthesis compared to saline exposed controls (M. Salmon, unpublished data). After repeated allergen challenge, there were three-fold increases in both ASM and epithelial cell BrdU incorporation indicating an increased rate of DNA synthesis compared to each of the control groups. The control groups had low rates of DNA synthesis in both ASM and epithelial cells indicating the relatively low turnover of these cells in the normal state. Following repeated allergen challenge, the highest BrdU indices were observed in the larger conducting airways that were examined (400-800 $\mu \mathrm{m}$ in diameter). This may be partly related to the greater density of mast cells present in the large airways compared to small distal airways following ovalbumin challenge in sensitized Brown-Norway rats [22]. Mast cells may contribute to bronchoconstriction through the release of mediators such as 5-hydroxytryptamine and cysteinyl-leukotrienes, but may also contribute to the increased proliferative responses by releasing proteases. Mast cell tryptase has been demonstrated to be mitogenic for ASM cells, epithelial cells and fibroblasts [23-25]. Furthermore, the preferential deposition of aerosolized ovalbumin in the larger proximal airways would also lead to a greater inflammatory response in these airways. Therefore, a combination of both these events may contribute to the observed gradient of DNA synthesis due to the intensity of the allergic reaction [26]. It is also possible, however, that ASM cells in the larger proximal airways have different proliferative properties compared to those in the more distal airways, as it has been established that there is heterogeneity of cells within the bronchial ASM population [27]. The observations of EBINA et al. [9] could support this concept, as they have described two independent pathogeneses for ASM thickening in asthmatic airways, which exhibit differential rates of hyperplasia and hypertrophy along the bronchial tree.

The mechanisms by which proliferation of ASM and epithelium occurs are poorly understood. Although the mast cell is likely to be one of the initiating cells in IgEmediated inflammation and can release mitogenic factors, other cells including eosinophils and macrophages are likely to be involved. In human airway smooth muscle, a number of growth factors such as epidermal growth factor [28], thrombin [28] and platelet-derived growth factor [29] have been demonstrated to induce proliferation in vitro. Other mediators released during inflammation can also potentiate ASM cell proliferation including the bronchoconstrictor agents histamine [30] and endothelin1 [31-33], and the pro-inflammatory cytokines, such as tumour necrosis factor- $\alpha$ [34] and interleukin-1 $\beta$ with IL6 [35]. The possibility that in vivo, proliferative activity may result from the interaction of combinations of various factors cannot, however, be precluded.

It is not clear whether proliferation of epithelial cells is induced by similar growth factors to ASM or by other mechanisms. Mediators that have been implicated in epithelial cell mitogenesis are endothelin-1 [36], IL-1 $\beta$ [37] and tachykinins [38]. Another likely mechanism for the proliferative response of epithelial cells may be in response to epithelial damage leading to basal cell metaplasia and increased proliferation of adjacent cells to facilitate epithelial repair [39].

The increase in ASM cell DNA synthesis was accompanied by a small but nonsignificant increase in ASM thickness. In a recent study using three allergen challenges 5 days apart, increases in ASM mass were detected in both large and medium sized airways [13]. There are several possible reasons why a significant increase in airway smooth muscle thickness was not detected in this study. Firstly, the power of the analysis may not have been great enough to detect significant increases in ASM thickness. Alternatively, there may be a temporal delay between the appearance of an increase in ASM cell number and an increase in ASM area. It is also conceivable that increases in ASM cell proliferation may be accompanied by a similar degree of cell death due to apoptosis. Further studies are required to examine these possibilities.

In summary, following six repeated allergen challenges of sensitized Brown-Norway rats, increased rates of deoxyribonucleic acid synthesis in airway smooth muscle and epithelial cells were detected, indicating increased cell proliferation responses. Larger airways had greater rates of deoxyribonucleic acid synthesis. Pathological changes in the airways were also detected including inflammatory cell recruitment, increased subepithelial collagen deposition, goblet cell hyperplasia and hypertrophy, and elevated levels of mucus in the airways. This model may therefore be useful for studying the structural changes that occur in the airways induced by chronic inflammation and the mechanisms which underlie airway wall remodelling.

Acknowledgements. The authors would like to thank L. Buttery from the Dept of Histochemistry, The Royal Postgraduate Medical School, Hammersmith Hospital for advice regarding bromodeoxyuridine immunohistochemistry, and S. Bottoms and M. Foster from the Dept of Pharmacology, Rhône-Poulenc Rorer, Dagenham for their assistance with the histological staining and interpretation of lung tissue pathology.

\section{References}

1. Djukanovic R, Wilson JW, Britten KM, et al. Quantitation of mast cells and eosinophils in the bronchial mucosa of symptomatic atopic asthmatics and healthy control subjects using immunohistochemistry. Am Rev Respir Dis 1990; 142: 863-871.

2. Bousquet J, Chanez P, Lacoste JY, et al. Eosinophilic inflammation in Asthma. NEnglJMed 1990; 323: 1033-1039. 
3. Azzawi $\mathrm{M}$, et al. Identification of activated T-lymphocytes and eosinophils in bronchial biopsies in stable atopic asthma. Am Rev Respir Dis 1990; 142: 1407-1413.

4. Dunnill MS, Massarella GR, Anderson JA. A comparison of the quantitative anatomy of the bronchi in normal subjects, in status asthmaticus, in chronic bronchitis, and in emphysema. Thorax 1969; 24: 176-179.

5. Aikawa T, Shimura S, Sasaki H, Ebina M, Takishima T. Marked goblet cell hyperplasia with mucus accumulation in the airways of patients who died of severe acute asthma attack. Chest 1992; 101: 916-921.

6. Laitinen LA, Heino M, Laitinen A, Kava T, Haahtela T. Damage of the airway epithelium and bronchial reactivity in patients with asthma. Am Rev Respir Dis 1985; 131 : 599-606.

7. Roche WR, Beasley R, Williams JH, Holgate ST. Subepithelial fibrosis in the bronchi of asthmatics. Lancet 1989; i: 520-524.

8. Heard BE, Hossain S. Hyperplasia of bronchial muscle in asthma. J Pathol 1973; 110: 319-331.

9. Ebina M, Takahashi T, Chiba T, Motomiya M. Cellular hypertrophy and hyperplasia of airway smooth muscles underlying bronchial asthma: a 3-D morphometric study. Am Rev Respir Dis 1993; 148: 720-726.

10. Padrid P, Snook S, Finucane T, et al. Persistent airway hyperresponsiveness and histologic alterations after chronic antigen challenge in cats. Am J Respir Crit Care Med 1995; 151: 184-193.

11. Blyth DI, Pedrick MS, Savage TJ, Hessel EM, Fattah D Lung inflammation and epithelial changes in a murine model of atopic asthma. Am J Respir Cell Mol Biol 1996; 14: 425-438.

12. Sapienza T, Du T, Eidelman DH, Wang NS, Martin JG. Structural changes in the airways of sensitised brownnorway rats after antigen challenge. Am Rev Respir Dis 1991; 144: 423-427.

13. Panettieri RA, Murray RK, Eszterhas AJ, Bilgen G, Martin JG. Repeated allergen inhalations induce DNA synthesis in airway smooth muscle and epithelial cells in vivo. Am J Physiol 1998; 274: 417-424.

14. Wang Z-L, Walker BAM, Weir TD, et al. Effect of chronic antigen and $\beta_{2}$ agonist exposure on airway remodelling in guinea pigs. Am J Respir Crit Care Med 1995; 152: 2097-2104.

15. Lendrum AC, Fraser DS, Slidders W, Henderson R. Studies on the character and staining of fibrin. $J$ Clin Pathol 1962; 15: 401

16. McManus JFA. Histological demonstration of mucin after periodic acid. Nature 1946; 158: 202.

17. Haczku A, Moqbel R, Jacobsen M, Kay AB, Barnes PJ, Chung KF. T-cells subsets and activation in bronchial mucosa of sensitised Brown-Norway rats after single allergen exposure. Immunology 1995; 85: 591-597.

18. Walsh DA, Hu DE, Mapp PI, Polak JM, Blake DR, Fan TP. Innervation and neurokinin receptors during angiogenesis in the rat sponge granuloma. Histochem J 1996; 28: 759-769.

19. Shu SY, Ju G, Fan LZ. The glucose oxidase-DAB-nickel method in peroxidase histochemistry of the central nervous system. Neurosci Lett 1988; 85: 169-171.

20. Murdoch A, Jenkinson EJ, Johnson GD, Owen JJT. Alkaline phosphatase-Fast Red, a new fluorescent label: application in double labelling for cell surface antigen and cell cycle analysis. J Immunol Methods 1990; 132: 45-49.

21. Jeffery PK, Wardlaw AJ, Nelson FC, Collins JV, Holgate ST. Bronchial biopsies in asthma: an ultrastructural, quantitative study and correlation with hyperreactivity. Am Rev Respir Dis 1989; 140: 1745-1753.

22. Du T, Sapienza S, Eidelman DH, Wang NS, Martin JG.
Morphometry of the airways during late responses to antigen challenge in the rat. Am Rev Respir Dis 1991; 143: 132-137.

23. Brown JK, Tyler CL, Jones CA, Ruoss SJ, Hartmann T, Caughey GH. Tryptase, the dominant secretory granular protein in human mast cells, is a potent mitogen for cultured dog tracheal smooth muscle cells. Am J Respir Cell Mol Biol 1995; 13: 227-236.

24. Cairns JA, Walls AF. Mast cell tryptase is a mitogen for epithelial cells: stimulation of IL-8 production and intercellular adhesion molecule-1 expression. J Immunol 1996; 156: 275-283.

25. Ruoss SJ, Hartmann T, Caughey GH. Mast cell tryptase is a mitogen for cultured fibroblasts. J Clin Invest 1991; 88: 493-499.

26. Martin JG, Bai TR. In vivo models of smooth muscle growth. In: Stewart AG, ed. Airway wall remodelling in asthma. CRC Press: Boca Raton, 1997, pp. 213-226.

27. Stephens NL, Halayko AJ. Airway smooth muscle contractile, regulatory and cytoskeletal protein expression in health and disease. Comp Biochem Physiol B Biochem Mol Biol 1998; 119: 415-424.

28. Tomlinson PR, Wilson JW, Stewart AG. Inhibition by salbutamol of the proliferation of human airway smooth muscle cells grown in culture. Br J Pharmacol 1994; 111: 641-647.

29. Hirst SJ, Barnes PJ, Twort CHC. Quantifying proliferation of cultured human and rabbit airway smooth muscle in response to serum and platelet-derived growth factor. Am J Respir Cell Mol Biol 1992; 7: 574-581.

30. Panettieri RA, Yadvish PA, Kelly AM, Rubenstein NA, Kotlikoff MI. Histamine stimulates proliferation of airway smooth muscle and induces c-fos expression. $\mathrm{Am} \mathrm{J}$ Physiol 1990; 259: 365-371.

31. Glassberg MK, Ergul A, Wanner A, Puett D. Endothelin1 promotes mitogenesis in airway smooth muscle cells. Am J Respir Cell Mol Biol 1994; 10: 316-321.

32. Noveral JP, Rosenburg SM, Anbar NA, Pawlowski NA, Grunstein MM. Role of endothelin-1 in regulating proliferation of cultured rabbit airway smooth muscle. Am J Physiol 1992; 263: L317-L324.

33. Panettieri RA, Goldie RG, Rigby PJ, Eszterhas AJ, Hay DWP. Endothelin-1-induced potentiation of human airway smooth muscle proliferation: an ETA receptor-mediated phenomenon. Br J Pharmacol 1996; 118: 191-197.

34. Stewart AG, Tomlinson PR, Fernandes DJ, Wilson JW, Harris T. Tumour necrosis factor- $\alpha$ modulates mitogenic responses to human cultured airway smooth muscle. $\mathrm{Am} J$ Respir Cell Mol Biol 1995; 12: 110-119.

35. De S, Zelazny ET, Souhrada JF, Souhrada M. IL-1 $\beta$ and IL-6 induce hyperplasia and hypertrophy of cultured guinea pig airway smooth muscle cells. J Appl Physiol 1995; 78: 1555-1563.

36. Murlas CG, Gulati A, Singh G, Najmabadi F. Endothelin1 stimulates proliferation of normal airway epithelial cells. Biochem Biophys Res Comm 1995; 212: 953-959.

37. Murlas CG, Sharma AC, Gulati A, Najmabadi F. Interleukin- $1 \beta$ increases airway epithelial cell mitogenesis partly by stimulating endothelin-1 production. Lung 1997; 175: 117-126.

38. Kim JS, Rabe KF, Magnussen H, Green JM, White SR. Migration and proliferation of guinea pig and human airway epithelial cells in response to tachykinins. $\mathrm{Am} \mathrm{J}$ Physiol 1995; 269: L119-L126.

39. Erjfalt JS, Korsgren M, Nilsson MC, Sundler F, Persson CG. Prompt epithelial damage and restitution processes in allergen challenged guinea-pig trachea in vivo. Clin Exp Allergy 1997; 27: 1458-1470. 